\title{
Small Electric Vehicles (SEV)_Impacts of an Increasing SEV Fleet on the Electric Load and Grid
}

\author{
Tobias Gorges, Claudia Weißmann, and Sebastian Bothor
}

\begin{abstract}
Heading towards climate neutrality, the electrification of the transport sector has significant impact on the electric grid infrastructure. Among other vehicles, the increasing number of new technologies, mobility offers, and services has an impact on the grid infrastructure. The purpose of this case study therefore is to examine and highlight the small electric vehicle (SEV) impact on the electric load and grid. A data-based analysis model with high charging demand in an energy network is developed that includes renewable energy production and a charging process of a whole SEV fleet during the daily electricity demand peak for the city of Stuttgart (Germany). Key figures are gathered and analysed from official statistics and open data sources. The resulting load increase due to the SEV development is determined and the impact on the electric grid in comparison to battery electric vehicles $(\mathrm{BEV})$ is assessed for two district types. The case study shows that if SEVs replace BEVs, the effects on the grid peak load are considered significant. However, the implementation of a load management system may have an even higher influence on peak load reduction. Finally, recommendations for the future national and international development of SEV fleets are summarized.
\end{abstract}

Keywords Grid peak load $\cdot \mathrm{SEV} \cdot \mathrm{BEV} \cdot$ Electric grid · Grid stability

T. Gorges $(\bowtie)$

MHP Management- und IT-Beratung, Berlin, Germany

e-mail: tobias.gorges@mhp.com

C. Weißmann

MHP Management- und IT-Beratung, Frankfurt am Main, Germany

S. Bothor

MHP Management- und IT-Beratung, Ludwigsburg, Germany

(C) The Author(s) 2021

A. Ewert et al. (eds.), Small Electric Vehicles,

https://doi.org/10.1007/978-3-030-65843-4_9 


\section{Introduction}

Heading towards climate neutrality, which the German Government is aiming to achieve by 2050 , the electrification of the transport sector has a significant impact on the electric grid infrastructure. Besides the increasing number of existing electric vehicles, new technologies, mobility services as well as small electric vehicles (SEV) need to be considered to assess the total impact on the grid infrastructure.

In the last few years, the fleet of SEVs increased by total number and type of vehicles. SEVs are emerging particularly in urban areas and are being more and more frequently rolled out as part of mobility-as-a-service approaches [1]. The growing SEV trend is predicted to continue up until 2030. Hence, this chapter will focus specifically on SEVs and their impact on the grid as well as the additional electricity demand and other factors of increasing grid stability uncertainty.

To examine and highlight the SEV impact on the grid infrastructure, the load capacity of a SEV fleet and its impact on the electric grid in 2020 and 2030 is calculated based on certain assumption in this study. Therefore, the charging process of the whole SEV fleet is modelled during the daily electricity peak demand. Vehicle replacement effects are taken into account and scenarios considering the fleet of battery electric vehicles (BEV) are modelled in this analysis.

To assess the SEV impact on the grid infrastructure, a data-based analysis model is set up and key figures like peak loads are gathered and analysed from official statistics and open data sources. As a study area the city of Stuttgart has been chosen, located in southern Germany and surrounded by a highly industrialized urbanized region with high electricity demand.

The determined charging capacity is compared with the load curve of a transmission system operator and the resulting load increase due to the SEV development is then calculated. Further, three scenarios are modelled by the modification of variables, hence the impacts on the grid infrastructure can be derived and recommendations for the future national and international development of SEV fleets can be drawn.

To conclude, this chapter derives answers to the following key questions: How much additional load capacity from SEVs considering the assumed development in the upcoming years can be expected by 2030? What are the impact differences between a purely BEV fleet and a mixed vehicle fleet of BEVs replaced by SEVs? Finally, how large is the difference in peak electric load between an SEV replacement in a BEV fleet versus load management? 


\section{Status Quo SEV and Grip Impact}

Recent studies currently consider both mobility concepts and vehicle concepts when assessing ways to advance the transport system as a whole. Both concepts are driven by the current trends in mobility, such as: electric mobility, shared economy, digitalization, and autonomous driving [2-5].

However, the introduction of new concepts often is accompanied with challenges concerning the integration into the existing system such as the infrastructure. Due to this reason, an ever increasing amount of impact assessment research on the integration of new concepts in the mobility sector and their design is continuously published. The impact as well as the design of the proposed concepts is predominantly modelled. For instance, Alazzawi et al. determine the optimal fleet size of a shared autonomous vehicle concept for Milan [6].

The integration of electric mobility into the grid is one major research field. The central challenge of this field is: stabilization of the grid with consideration to the ranging power demand and production as well as additional spatial and time-related difference [7-10].

For instance, Morais et al. consider different scenarios of EV's impact in the power demand curve in a smart grid with vehicle-to-grid capabilities [11]. Bastida-Molina et al. assess charging strategies for light electric vehicles to exploit the existing electric generation system as best as possible [12]. Research on grid impact has predominantly been based on conventional-sized vehicle concepts and their battery characteristics. However, the impact and integration potential of different electrified vehicle concepts to ensure grid stability and especially peak load demand should have also been assessed.

Foresight, electrified autonomous vehicles and their already predicted impact on infrastructure, processes and culture [13, 14] would trigger a change of travel behaviour and travel choices $[15,16]$ to have a potential impact on SEVs. SEV, as new vehicle concept and pointed out in the preface and in the chapter "Small electric vehicles-benefits and drawbacks" of this book differ from BEVs, for example, in terms of their vehicle weight and thus battery and load capacity. Therefore, they have a certain potential for improving existing challenges of current transport systems. Hence, this chapter focuses on a prediction of the impact of an SEV fleet on the grid.

\section{Method}

The current available SEV concepts and their characteristics, such as seating capacity, maximum velocity, required driving licence, weather protection, predominant use (passenger or goods transport), volume of goods, determine the parameter set for the assessment of the potential for trip usage. This methodology is an adaptation of the approach used in the SEV study by Brost et al. [17] and data 
Table 1 Overview of SEV use and development

\begin{tabular}{l|l|l|l}
\hline $\begin{array}{l}\text { Trip } \\
\text { purpose }\end{array}$ & $\begin{array}{l}\text { Trip distance } \\
(\mathrm{km})\end{array}$ & Number of SEVs by 2020 & Number of SEVs by 2030 \\
\hline Business & 20.1 & 30 & 665 \\
\hline Shopping & 9.1 & 58 & 1264 \\
\hline Leisure & 13.0 & 38 & 823 \\
\hline
\end{tabular}

retrieved from a mobility study in Germany (Mobilität in Deutschland (MiD), 2017) [18]. The identified trips with SEV potential are clustered by trip purpose. Mobility profiles throughout the day are developed serving as basis for the energy calculations. Besides the SEV fleet, the BEV fleet and its size in 2030 are calculated for the study location, Stuttgart in Germany. The results are integrated into a scenario analysis in chapter The UK Approach to Greater Market Acceptance of Powered Light Vehicles (PLVs).

Trip distances that are derived from the MiD are assumed to be equivalent in the future and differ between the three categorized trip purposes. It is assumed that an SEV can be assigned to one of these three predominant trip purpose categories, the total number of SEVs on each trip purpose is then determined. Numbers of SEVs in Stuttgart are predicted to rise up to a stock of 2800 by 2030 which equals more than 35,500 driven passenger-kilometres per day, as listed by Table 1 . As only limited data on the SEV market and its future development is available, the SEV fleet size for 2030 is calculated using the same ramp-up time of BEVs.

In a second step, the corresponding electricity consumption and charging time is calculated in order to create a representative charging load profile for the scenario analysis (see Table 2).

The average electricity consumption of an SEV is $7.5 \mathrm{kWh} / 100 \mathrm{~km}$ and it is typically charged with a standard shockproof plug at $2.4 \mathrm{~kW}$ [17]. In comparison with this charging standard, an average BEV has a much higher consumption rate of about $20 \mathrm{kWh} / 100 \mathrm{~km}$ due to higher mass and speed [19]. BEVs can be charged via charging stations with higher loads.

In a third step, the calculated load profiles are applied to electricity grid branches for the assessment of the SEV impact. Different SEV usage scenarios and thus an increase of charging load are considered. As SEVs have a different impact on the grid than BEVs, the peak demand from SEVs and therefore necessary grid improvements and other measures are dependent on SEV usage.

Table 2 Overview of SEV electricity consumption and charging time

\begin{tabular}{l|l|l}
\hline Trip purpose & Trip consumption $(\mathrm{kWh})$ & Equivalent charging time $(\mathrm{min})$ \\
\hline Business & 1.51 & 38 \\
\hline Shopping & 0.68 & 17 \\
\hline Leisure & 0.98 & 24 \\
\hline
\end{tabular}




\section{Case Study Stuttgart}

Located in southwestern Germany in a valley basin, the city of Stuttgart contains a dense road network with a high amount of cars (301,793 vehicle registrations to 620,445 residents) $[20,21]$. The shift towards electric mobility is ongoing with 3365 electric vehicles (battery electric and plug-in hybrid vehicles) on the road in 2019. Concerning the electric grid, about 90,000 power connections currently exist. About $97 \%$ of the power connections are realized using underground electric cables. This implies high costs in case of increasing the city's energy transport capacity due to necessary ground works.

To assess the impact of an SEV fleet on the grid, three different scenarios are created. Scenario 1, as the baseline scenario considers trips using BEVs only not including any SEV transportation. Scenario 2 is constructed around the assumption of trips using a fleet of SEVs and BEVs. However, here, the SEV trips do not replace the BEV trips but increase the total vehicle number on the road (worst case). In contrast to that, Scenario 3 describes a best-case trip scenario with an SEV fleet that is used for current car trips and can therefore replace some of the BEVs that would have otherwise been required on the roads.

The assessment focus for the impact analysis of SEVs on electricity grids in these scenarios is the change in peak demand in the city area as a whole and also in specific branches of the grid. In addition, the impact of the controllability of charging processes will be assessed.

Table 3 shows the parameters applied within the scenario analysis. The absolute number of BEVs describes the number of electric cars in Stuttgart including plug-in hybrids. In 2020, 3,365 BEVs exist in Stuttgart which corresponds to a local vehicle share of about $1 \%$ [20]. It is predicted that the BEV share will increase up to $24 \%$ or 73,514 by $2030[22,23]$ considering a total vehicle increase of about $1.2 \%$ due to urbanization [24]. The BEV calculation is described in detail in Weissmann and Gorges [23].

The scenario analysis focuses on the overnight charging process at a private charging point. According to the MiD study the average vehicle typically arrives at home at 08:00 PM and leaves at 07:00 AM, which determines the plug-in timespan. It is assumed that SEVs are charged with a standard shockproof plug at $2.4 \mathrm{~kW}$ while BEVs are charged via a $11 \mathrm{~kW}$ charging station (charging stations with higher delivery rates are neglected as they are not assumed to be economically

Table 3 Scenario parameters (without substitution)

\begin{tabular}{l|c|l|l|l}
\hline \multirow{2}{*}{ Vehicle type } & 2020 & 2030 & \\
\cline { 2 - 5 } & BEV & SEV & BEV & SEV \\
\hline Absolute number & 3365 & 126 & 73,514 & 2800 \\
\hline $\begin{array}{l}\text { Maximum charging } \\
\text { load }(\mathrm{kW})\end{array}$ & 37,000 & 300 & 808,700 & 6600 \\
\hline
\end{tabular}




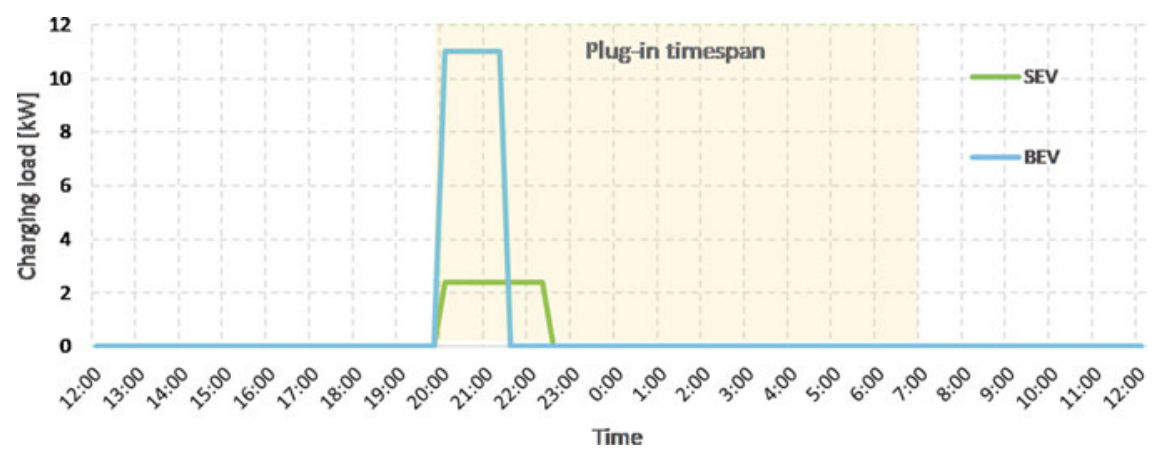

Fig. 1 Exemplary SEV and BEV charging profile (Charging after four "Business" trips, see Table 2)

efficient for the long overnight timespan) which can be controlled with a charging management system via a CPO-backend. Regarding controllability, this implies that the charging process of BEVs is controllable while the SEV charging is completely dependent on user behaviour.

For estimating the maximum possible charging load, a simultaneity factor of 1 has to be assumed for electric vehicles without charging management [25]. The overall effect of a charging management system on parallel charging cannot be quantified yet. Figure 1 illustrates an exemplary charging profile of a BEV and an SEV.

Based on these charging profiles and the scenario parameters of Table 3, maximum charging power loads are calculated. The results are shown in Table 4. SEVs have a total charging load of about 7 MW in 2030 (Scenario 2). However, assuming that SEVs will actually replace BEVs (Scenario 3) a total load reduction of approximately 24 MW could be achieved in 2030 .

With the $11 \mathrm{~kW}$ charging technology for BEV charging, the increase of the maximum load up until 2030 is considerably high. Especially, if it is assumed that charging procedures will be started right at the beginning of the plug-in timespan (as in Fig. 2), the charging peak would correspond to the peak of the standard load profile of German households (H0 profile, see [26]). Considering an estimated peak demand of about $800 \mathrm{MW}^{1}$ of private households in the case study scope today, the total resulting peak demand could become twice as high by 2030 [27].

In order to derive the impact of additional charging loads on the city peak demand, two typical low voltage network branches are analysed. One branch supplies early adopters and therefore is located in an outlying district of the city with a small number of households per residential building in general. The other is assumed to be located in a central area of the city with residential buildings and a higher number of households per building. In the latter case, the rate of EV

\footnotetext{
${ }^{1} 390,000$ electric meters $\times 10 \mathrm{~kW}$ peak load per meter $\times 0.2$ simultaneity factor.
} 
Table 4 Maximum charging load-Scenario perspective

\begin{tabular}{l|l|l|l}
\hline \multirow{2}{*}{ Scenario } & Scenario 1 & Scenario 2 & Scenario 3 \\
\cline { 2 - 4 } & BEVs only & $\begin{array}{l}\text { BEVs plus } \\
\text { SEVs }\end{array}$ & $\begin{array}{l}\text { SEVs replace } \\
\text { BEVs }\end{array}$ \\
\hline $\begin{array}{l}\text { Maximum grid charging load 2020 } \\
(\mathrm{kW})\end{array}$ & 37,000 & 37,300 & 35,900 \\
\hline $\begin{array}{l}\text { Maximum grid charging load 2030 } \\
(\mathrm{kW})\end{array}$ & 808,700 & 815,300 & 785,000 \\
\hline
\end{tabular}

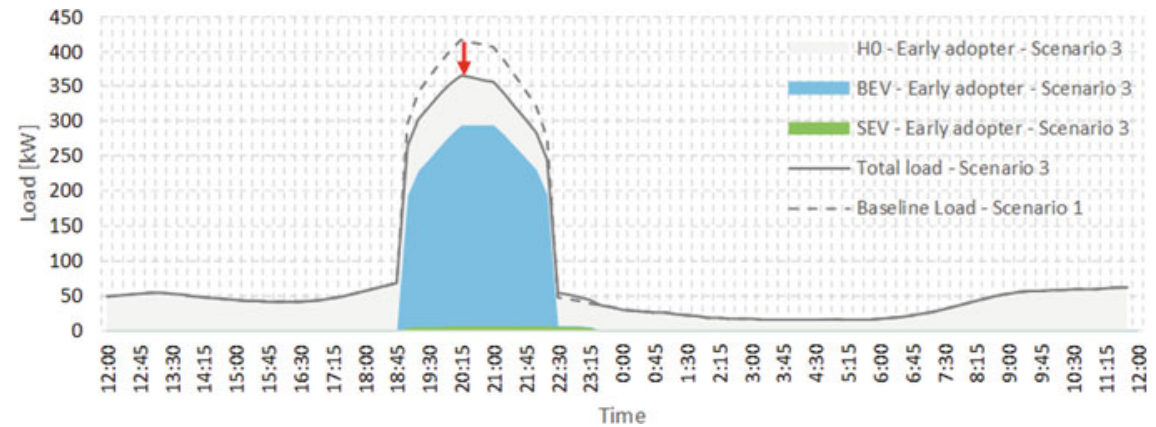

Fig. 2 Total load reduction in Scenario 3 compared to Scenario 1 (Early adopter, outlying district) H0 BDEW household load profile according to [26]; Distribution of charging timespan according to [28]

adoption is considered to be lower. Another main difference of these two branches is the number of cars per inhabitant. There are 424 cars per 1,000 inhabitants in the early adopter's branch, which is significantly lower than the 307 cars in the inner city, with a city wide average of 365 cars per 1,000 inhabitants [24].

Table 5 illustrates the possible increase of the peak load for both branch cases in each scenario. In Scenario 1, the baseline BEVs-only scenario, the increase of the peak demand is generally high. In addition, the socio-demographic difference between the two cases is shown as the peak demand increases about 50\% in the average adopter street and almost three times as high in the early adopter street.

Table 5 Peak demand increase in hypothetical branches*-Scenario perspective

\begin{tabular}{l|l|l|l}
\hline Scenario for 2030 & Scenario 1 & Scenario 2 & Scenario 3 \\
\cline { 2 - 4 } & $\begin{array}{l}\text { BEVs only } \\
(\%)\end{array}$ & $\begin{array}{l}\text { BEVs plus } \\
\text { SEVs (\%) }\end{array}$ & $\begin{array}{l}\text { SEVs replace } \\
\text { BEVs (\%) }\end{array}$ \\
\hline $\begin{array}{l}\text { Increase of peak demand - average } \\
\text { adopters street, inner city }\end{array}$ & 48 & 52 & 30 \\
\hline $\begin{array}{l}\text { Increase of peak demand - early adopters } \\
\text { street, outlying district }\end{array}$ & 190 & 197 & 167 \\
\hline
\end{tabular}

*Based on the worst-case assumption of simultaneity charging factor of 1 
In contrast to this large difference, the results in Scenario 2 are almost similar to those of Scenario 1. This is a result of the assumption that SEVs are charged with only $22 \%$ of the charging power used for BEVs. Therefore, the increase of the peak demand in a typical branch can be almost totally explained by the charging of BEVs. Hence, an additional use of SEVs as assumed in Scenario 2 does not have a major additional negative impact on the grid.

The focus of Scenario 3 is if SEVs could have a positive effect on the grid instead, by replacing trips made by BEVs. A maximum substitution rate of $4 \%$ of the BEVs is assumed (see Table 3). Table 5 shows that due to substitution, especially in the average adopter street in the inner city a significantly lower peak demand with only $30 \%$ increase is calculated. On the other hand, the early adopter street in the outlying district a very high range of additional peak demand (167\%) might still occur due to electric vehicle extension.

Figure 2 depicts the possible load reduction in Scenario 3 for this early adopter branch in comparison to the baseline Scenario 1. Here, a peak load reduction of about $50 \mathrm{~kW}$ can be achieved by SEV substitution (see red arrow). These effects of substitution are considered significant and will have not only an overall, but also various local neutralizing impacts. Lower investments in grid developments might therefore be sufficient in some streets and grid branches and less total restructuring necessary as well as less civil engineering interference with daily city life. As a result, advantages will occur within grid branches with higher SEV substitution levels.

On the other hand, there will still be a high number of branches requiring grid development due to the strong BEV uptake. Even if SEVs replace $20 \%$ of BEV trips, a very high level of additional load is still likely to be served through the physical electricity grid of the city branches. As a conclusion, SEVs can only partly neutralize intense grid peak demand situations in future.

However, one should keep in mind that the peak load values are derived using a worst case assumption with a simultaneity factor equal to 1 for charging. With future charging management systems, the controllable BEV loads could be distributed over longer timespans (until 7:00 AM in the morning) which would result in a possible BEV peak load reduction of approximately $70 \%$ (the blue BEV loads within the $3.5 \mathrm{~h}$ charging time-span could be equally distributed over the plug-in timespan of $11 \mathrm{~h}$, see Fig. 2) as well as in a total load reduction. Looking at Fig. 2, one can conclude, that the grid advantages due to charging management could be higher than the impact due to SEV trip replacement, which reduces peak load by $15 \%$.

\section{Conclusion}

The aim of this chapter has been to assess the impact of SEVs on the electric grid, assuming that the electric grid will be stressed by electric mobility in general in the future. In chapters Courses of Action for Improving the Safety of the Powered Cycle and Velomobiles and Urban Mobility: Opportunities and Challenges, the 
status quo of SEVs is described. Feasible SEV trip purposes have been identified to derive the potential for SEVs to replace BEVs.

A scenario analysis has been conducted for the city of Stuttgart to calculate the SEV grid impact in chapter The UK Approach to Greater Market Acceptance of Powered Light Vehicles (PLVs), focusing two city districts with different socio-demographic conditions. Within the scenario scope, a BEV-only extension (as a baseline) has been compared to a BEV increase with additional SEVs and a BEV increase utilizing SEVs to replace a certain percentage of trips.

The analysis shows that the impact of electric vehicles on the total grid load in general is very high, implying the requirement for essential measures to secure grid stability in the long run. The negative effect of additional SEV load is however negligible (Scenario 2) as the occurring electric vehicle peak loads in 2030 are mainly driven by BEV charging. This is a result of the much higher absolute number of BEVs compared to SEVs as well as much lower load peaks of singular SEVs $(2.4 \mathrm{~kW})$ compared to singular BEVs (11 kW). Moreover, SEVs may have a positive effect on grid stability when used to replace BEV trips (Scenario 3). Especially, in outlying city districts with early adopters to electric mobility and likewise an accelerated BEV and SEV increase, this effect is significant. Nevertheless, the analysis also has pointed out that charging management as another grid stabilization measure may have a higher impact (70\% BEV peak load reduction) on total peak load reduction than SEV substitution effects as the assumed share of SEVs in 2030 is still rather low.

There are certainly some limitations of this chapter due to a lack of SEV data in comparison to existing BEV data. Nevertheless, the authors conducted this study as accurately as possible with the available data. With an increasing data quantity and quality on current and future SEV fleets, the assumptions of the chapter, such as the defined vehicle characteristics and fleet size, as well as their impact on the electric grid could be verified and assessed in more detail respectively. For example, there could occur a much higher SEV extension in reality, due to the fact that SEV extension is not linked to the development of proper charging infrastructure like BEV extension.

Another aspect that should be considered in future research is the low controllability of the SEV charging processes via shockproof wall sockets. Based on the assumption that SEV will be mainly charged at low power (3.7-7.2 $\mathrm{kW}$ ) at wall sockets, charging controllability is only possible if there is an available control signal from the grid operator or aggregator. As charging controllability is a prerequisite for the best utilization of BEV local or wider grid services, just as congestion management or ancillary services are, the SEV contribution to this type of grid stability measure is currently little to none. A possible improvement for SEVs could be an adaptation of BEV backend technology to control the charging process by grid operator signals. With a significant SEV fleet, likewise another positive grid effect could be created.

Finally, as the number and popularity of SEVs increases, more information on the usage of SEVs should become available (such as specific trip characteristics and changing mobility behaviour) and could be considered in future research. Aligned with the changing mobility sector in general, this, however, will be a continuous research topic. 


\section{References}

1. Giesecke, R., Surakka, T., Hakonen, M.: Conceptualising mobility as a service. In: 2016 11th International conference on ecological vehicles and renewable energies, EVER 2016, January 2018 (2016). https://doi.org/10.1109/EVER.2016.7476443

2. Burns, L.D., Jordan, W.C., Scarborough, B.A.: Program on sustainable mobility the Earth Institute, Columbia University, pp. 1-43 (2013)

3. Fagnant, D.J., Kockelman, K.: Preparing a nation for autonomous vehicles: opportunities, barriers and policy recommendations for capitalizing on self-driven vehicles. Transp. Res. 77 (Part A), 167-181 (2015)

4. Fagnant, D., Kockelman, K.M.: The travel and environmental implications of shared autonomous vehicles, using agent-based model scenarios. Transp. Res. Part C 40, 1-13 (2014). https://doi.org/10.1016/j.trc.2013.12.001

5. Jaekel, M., Bronnert, K.: Die digitale Evolution moderner Großstädte (2013). https://doi.org/ 10.1007/978-3-658-00171-1

6. Alazzawi, S., Hummel, M., Kordt, P., Sickenberger, T., Wieseotte, C., Wohak, O.: Simulating the impact of shared, autonomous vehicles on urban mobility - a case study of Milan. 2, 9476 (2018). https://doi.org/10.29007/2n4h

7. BDEW: Elektromobilität braucht Netzinfrastruktur. Netzanschluss und-integration von Elektromobilität. https://www.bdew.de/media/documents/Stn_20170615_NetztintegrationElektromobilitaet.pdf (2017)

8. Bundesnetzagentur: Bericht zum Zustand und Ausbau der Verteilernetze 2018 (2018)

9. Friedl, G., Walcher, F., Stäglich, J., Fritz, T., Manteuffel, D.: Blackout-e-mobilität setzt Netzbetreiber unter Druck (2018)

10. Nobis, P., Fischhaber, S.: Belastung der Stromnetze durch Elektromobilität. Belastung Der Stromnetze Durch Elektromobilität, 3 (2015)

11. Morais, H., Sousa, T., Vale, Z., Faria, P.: Evaluation of the electric vehicle impact in the power demand curve in a smart grid environment. Energy Convers. Manag. 82, 268-282 (2014). https://doi.org/10.1016/j.enconman.2014.03.032

12. Bastida-Molina, P., Hurtado-Pérez, E., Pérez-Navarro, Á., et al.: Light electric vehicle charging strategy for low impact on the grid. Environ. Sci. Pollut. Res. (2020)

13. Bauer, G.S., Greenblatt, J.B., Gerke, B.F.: Cost, energy, and environmental impact of automated electric taxi fleets in Manhattan. Environ. Sci. Technol. 52(8), 4920-4928 (2018). https://doi.org/10.1021/acs.est.7b04732

14. Sprei, F.: Disrupting mobility. Energy Res. Soc. Sci. 37, 238-242 (2018). https://doi.org/10. 1016/j.erss.2017.10.029

15. Fraunhofer IAO, Horváth Partners: The value of time-Nutzerbezogene Service-Potenziale durch autonomes Fahren, vol. 80, issue April (2016)

16. Soteropoulos, A., Berger, M., Ciari, F.: Impacts of automated vehicles on travel behaviour and land use: an international review of modelling studies. Transp. Rev. 39(1), 29-49 (2019). https://doi.org/10.1080/01441647.2018.1523253

17. Brost, M., Ewert, A., Schmid, S., Stieler, S., Eisenmann, C., Klauenberg, J., Gruber, J.: Elektrische Klein- und Leichtfahrzeuge - Chancen und Potentiale für Baden-Württemberg on behalf of e-mobil BW (2019)

18. Nobis, C., Kuhnimhof, T.: Mobilität in Deutschland-MiD Ergebnisbericht (2018)

19. ADAC: Aktuelle Elektroautos im Test: So hoch ist der Stromverbrauch. https://www.adac.de/ rund-ums-fahrzeug/tests/elektromobilitaet/stromverbrauch-elektroautos-adac-test/ (2020). Accessed 31.07.2020

20. Kraftfahrbundesamt: Bestand am 1. Januar 2019 nach Zulassungsbezirken und Gemeinden. Bestand an Kraftfahrzeugen Und Kraftfahrzeuganhängern Nach Zulassungs-bezirken. https:// www.kba.de/DE/Statistik/Fahrzeuge/Bestand/ZulassungsbezirkeGemeinden/ zulassungsbezirke_node.html (2019). Accessed 31.07.2020 
21. Statistisches Amt Stuttgart: Fortgeschriebene Einwohnerzahl in Stuttgart 2019 nach Staatsangehörigkeit und Geschlecht. https://www.stuttgart.de/item/show/688662/1 (2019). Accessed 31.07.2020

22. Gerbert, P., Herhold, P., Burchardt, J., Schönberger, S., Rechenmacher, F., Kirchner, A., Kemmler, A., Wünsch, M.: Klimapfade für Deutschland. In: BDI-Bundesverband der Deutschen Industrie e. V., BCG-The Boston Consulting Group, Prognos. https://bdi.eu/ publikation/news/klimapfade-fuer-deutschland/ (2018). Accessed 31.07.2020

23. Weissmann, C., Gorges, T.: Entwicklung eines Planungstools zum regionalen Ladeinfrastrukturausbau. In: Realisierung Utility 4.0, Band 2: Praxis der digitalen Energie-wirtschaft von den Grundlagen bis zur Verteilung im Smart Grid (1. Auflage). Springer Vieweg (2019)

24. Statistisches Amt Stuttgart: Statistikatlas Stuttgart. https://statistik.stuttgart.de/statistiken/ statistikatlas/atlas/atlas.html?indikator=i0\&select=00 (2019). Accessed 31.07.2020

25. DIN 18015-1: Elektrische Anlagen in Wohngebäuden-Teil 1: Planungsgrundlagen (2018)

26. Meier, H., Fünfgeld, C., Adam, T., Schieferdecker, B.: Repräsentative VDEW-Lastprofile. Forschungsbericht (1999)

27. Stuttgart Netze GmbH: Elektromobilität in Stuttgart nutzen. https://www.stuttgart-netze.de/ netz-nutzen/themen/elektromobilitaet/ (2020). Accessed 31.07.2020

28. Eckstein, S., Buddeke, M., Merten, F.: Europäischer Lastgang 2050. Projektbericht zum Arbeitspaket 4: Regenerative Stromerzeugung und Speicherbedarf in 2050-Restore 2050 (2015)

Open Access This chapter is licensed under the terms of the Creative Commons Attribution 4.0 International License (http://creativecommons.org/licenses/by/4.0/), which permits use, sharing, adaptation, distribution and reproduction in any medium or format, as long as you give appropriate credit to the original author(s) and the source, provide a link to the Creative Commons license and indicate if changes were made.

The images or other third party material in this chapter are included in the chapter's Creative Commons license, unless indicated otherwise in a credit line to the material. If material is not included in the chapter's Creative Commons license and your intended use is not permitted by statutory regulation or exceeds the permitted use, you will need to obtain permission directly from the copyright holder.

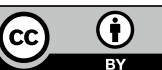

